DOI 10.5216/ia.v46i3.67945

\title{
"ESCREVIVÊNCIAS", NARRATIVAS AUTOBIOGRÁFICAS E INTELECTUALIDADE NEGRA: A ESCRITA ACADÊMICA COMO RESISTÊNCIA
}

\author{
LÁzARO de Oliveira EVANGelista \\ Universidade Federal do Rio Grande do Sul (UFRGS), Rio Grande, Rio Grande do Sul, Brasil \\ Carolina de Freitas CorrêA Siqueira \\ Universidade Federal do Rio Grande do Sul (UFRGS), Porto Alegre, Rio Grande do Sul, \\ Brasil \\ Cristianne Maria Famer Rocha \\ Universidade Federal do Rio Grande do Sul (UFRGS), Porto Alegre, Rio Grande do Sul, \\ Brasil
}

\begin{abstract}
Resumo: A partir de conceitos e referências dos estudos voltados à Educação das Relações Étnico-Raciais, este texto tem por objetivo realizar uma análise acerca do modo como o conceito de "Escrevivências", elaborado pela escritora e pensadora negra Conceição Evaristo, tem funcionado enquanto recurso teórico e metodológico para a produção e escrita de produções acadêmicas de pesquisadores/as negros/as. Para tanto, nos debruçamos sobre um conjunto de trabalhos acadêmicos divulgados no ambiente virtual da Associação Brasileira de Pesquisadores/as Negros/as e, a partir dos materiais selecionados, analisamos que a construção de narrativas autobiográficas negras, dentro do âmbito acadêmicocientífico, tem operado como um importante recurso teórico e metodológico no que tange um fazer e escrever ciência de modo protagonista, autoral, político e demarcadamente afirmativo por parte de pesquisadoras/es negras/os no Brasil contemporâneo.

Palavras-chave: Educação das Relações Étnico-Raciais. Narrativas de Si. Estudos Culturais.
\end{abstract}

INTRODUÇÃO

O contexto contemporâneo das lutas antirracistas no Brasil tem se solidificado, cada vez mais, sobretudo nas últimas duas décadas, por meio das importantes demandas pelo reconhecimento e valorização da diversidade ${ }^{1}$ a partir de um ponto de vista afirmativo das narrativas identitárias negras. De acordo com Petrônio Domingues (2005, p. 164), essa consolidação é resultado "da luta empreendida pelo movimento negro, [pois] há décadas assiste-se a uma mudança de postura, em vários segmentos da sociedade brasileira, em relação ao tratamento conferido às questões da população negra no país".

Nesse contexto, foram institucionalizados espaços públicos que objetivam a elaboração e efetivação de políticas antirracismo, haja vista a criação do Estatuto da Igualdade Racial (BRASIL, 2010), do Sistema Nacional de Promoção da Igualdade Racial (SNAPIR), e da Secretaria Especial de Promoção da Igualdade Racial (SEPPIR). A ambiência social que permitiu a emergência do aparato de Estado destinado ao 
reconhecimento e à valorização da população afro-brasileira criou condições para a inserção da temática étnico-racial no debate sobre as políticas educacionais.

Datam, também desse período, legislações que modificaram diretamente a atual estrutura educacional brasileira, como é o caso da Política de Cotas Raciais (BRASIL, 2012), que estipula o percentual das vagas disponíveis no ensino superior para indivíduos autodeclarados negros, assim como a legislação que institui a obrigatoriedade de ensino de História e Cultura Afro-Brasileira e Africana na educação básica (BRASIL, 2003). Alicerçados em uma estrutura que possibilita a produção de novas narrativas identitárias acerca das populações negras brasileiras, os movimentos negros ganham força e espaço para o fomento de ações que visam amplificar a valorização da negritude como estratégia de superação e combate do racismo. Assim, muitos foram os espaços requisitados pelos movimentos supracitados, pelos quais a desigualdade racial passa a ser posta em debate.

Nesse âmbito, o cenário do ensino superior começa a ser delineado de outras formas e, como desdobramento da entrada da temática étnico-racial nas estruturas de ensino básico e superior, o stricto sensu, posteriormente, se apresentou como novo campo de luta, resistência e produção de condutas afirmativas. A inscrição das pautas étnico-raciais nos espaços de pesquisa torna possível que sejam observados novos movimentos de luta por consolidação do espaço da intelectualidade negra na produção científica como estratégia de visibilidade e afirmação identitária.

Essas demandas podem ser verificadas, por exemplo, com a fundação da Associação Brasileira de Pesquisadores/as Negros/as (ABPN, 2002), assim como com o considerável aumento das publicações científicas, tais como teses e dissertações direcionadas aos estudos da Educação das Relações Étnico-Raciais (ERER) no Brasil. De acordo com Luiz Alberto Gonçalves e Petronilha Gonçalves Silva (2000), entre as décadas de 1980 e 1990, o volume de teses e dissertações que abordavam a temática da Educação e das Relações Étnico-Raciais não ultrapassou a marca de 20 trabalhos. Ahyas Siss e lolanda de Oliveira (2007), por sua vez, observam que a produção científica relacionada às Relações Étnico-Raciais, de autoria de pesquisadores autodeclarados negros ou não, acompanhou aumento importante a partir da década de 2000.

Em sua Tese de Doutorado, a pesquisadora Zuleika Kohle Gonzales (2015) aponta um levantamento de informações de estudos publicados no banco de teses da Coordenação de Aperfeiçoamento de Pessoal de Nível Superior (Capes) relacionados ao tema das Relações Étnico-Raciais. Os dados estatísticos levantados na pesquisa indicam que, durante o período de 2010 a 2015, houve um crescimento ainda maior no que tange o referido campo de estudos.

A consolidação das lutas pela virada epistemológica no pensamento científico afirmativo da negritude está intensamente calcada nos redimensionamentos das narrativas identitárias, conquistadas pelos movimentos sociais negros, pela militância e pelo princípio de protagonismo negro defendido por tais grupos. Assim, tendo em vista o contexto contemporâneo das lutas antirracistas inseridas no âmbito acadêmico, observamos, a partir de levantamento de estudos acadêmico-científicos divulgados na página da Associação Brasileira de Pesquisadores/as Negros/as, um relevante aumento 
de trabalhos científicos (de diferentes áreas do conhecimento) que lançam mão de narrativas autobiográficas e/ou de uma escrita que parte de experiências de si como modo de implicar-se e se colocar no texto.

Com essa percepção em vista, objetivamos, neste estudo, realizar uma analítica acerca de que modo o conceito de "Escrevivências", elaborado pela escritora e pensadora negra Conceição Evaristo (2017a, 2017b), tem funcionado como recurso teórico e metodológico para a produção e escrita de produções acadêmicas de pesquisadores/as negros/as. Assim, passamos a refletir a respeito da recorrência desse gênero de escrita como elemento teórico e também metodológico que propulsiona, intensifica e produz uma forma afirmativa por meio da qual pesquisadores/as negros/as vêm elaborando conhecimento científico. A escrita que parte de narrativas autobiográficas e experiências de si se apresenta de modo orgânico, produtivo e político. Para o desenvolvimento dessas análises, lançamos mão de alguns dos trabalhos acadêmicos divulgados no ambiente virtual da Associação Brasileira de Pesquisadores/as Negros/as.

Fundada em 2002, a Associação Brasileira de Pesquisadores/as Negros/as ${ }^{2}$ é apresentada no seu Estatuto (ABPN, 2002, Art. 1) como "uma associação civil, sem fins lucrativos, filantrópica, assistencial, cultural, científica e independente, tendo por finalidade o ensino, pesquisa e extensão acadêmico-científica sobre temas de interesse das populações negras do Brasil". Em seu Art. 4º, o Estatuto designa como finalidades da Associação:

\begin{abstract}
a) Congregar os Pesquisadores Negros Brasileiros; b) Congregar os Pesquisadores que desenvolvam investigações sobre temas de interesse das populações negras do Brasil; c) Assistir e defender os interesses da ABPN e de seus sócios, perante os poderes públicos em geral ou entidades autárquicas; d) Promover conferências, reuniões, cursos e debates relacionadas a temas de interesse das populações negras no Brasil; e) Possibilitar publicações de teses, dissertações, artigos, revistas de interesse direto das populações negras do Brasil; f) Estabelecer e manter intercâmbio com associações congêneres do país e do exterior; g) Defender e zelar pela manutenção da Pesquisa com financiamento Público e/ou privado, propondo medidas para seu aprimoramento, fortalecimento e consolidação; h) Propor medidas para a política de ciência e tecnologia do País (ABPN, 2002, Art. 4º).
\end{abstract}

A ABPN possui um ambiente virtual destinado a mobilizar e conglobar os pesquisadores que desenvolvam atividades de pesquisa vinculadas a temáticas relevantes às populações negras brasileiras. Como forma de visibilizar as produções científicas, a página oferece um espaço direcionado à divulgação de publicações sobre o tema das Relações Étnico-Raciais e afins. A seção destinada à divulgação dessas pesquisas é constituída pela Coleção Negros e Negras, composta por livros de autoria de pesquisadores negros/as e disponível para download; pelos Anais dos Congressos Brasileiros de Pesquisadores/as Negros/as, promovidos pela ABPN; pelos Catálogos de Diretórios de Núcleos e Grupos de Estudos sobre a Temática Étnico-Racial no Brasil; por uma Biblioteca Virtual, que contém 382 títulos de Filosofia, Sociologia, Teologia, 
Economia, Política e Literatura, também disponibilizados para download; por um Banco composto por 140 trabalhos, entre Teses, Dissertações e Trabalhos de Conclusão de Curso de pesquisadores/as associados/as à ABPN; e, por fim, pela Revista da ABPN.

\section{O CAMPO ACADÊMICO-INTELECTUAL ENQUANTO UM ESPAÇO DE LUTA}

As tensões coloniais enfrentadas por intelectuais negras e negros são intensificadas no âmbito acadêmico nacional, uma vez que esses espaços, no caso brasileiro, foram historicamente formatados para atender apenas a uma parcela mais privilegiada da sociedade, potencializando, assim, as assimetrias existentes no país. Em outras palavras, os espaços acadêmicos foram assimilados como loci repletos de cadeiras cativas e, a partir dessa perspectiva, se constituíram, como "redutos da branquidade" (OLIVEN; BELLO, 2017, p. 342).

Muniz Sodré (2015), ao refletir sobre o racismo e as identidades do povo brasileiro, articula conceitos entre sujeitos e seus territórios, uma vez que ambos estão diretamente condicionados às semelhanças fenotípicas e culturais. Nesse sentido, quando "o Outro" não é visto como semelhante, a ele é atribuída a acepção de "intruso".

$\mathrm{Na}$ trilha de problematizar esse quadro, se, por um lado, os espaços de intelectualidade acadêmica no Brasil não foram pensados para atender a sociedade de forma a considerar a sua diversidade étnico-racial, por outro, as populações negras tem empreendido importantes esforços para tornar o campo acadêmico, cada vez mais, um território de lutas antirracistas, por meio de uma produção científica protagonizada por pesquisadoras/es negras/os. Os cenários de produção intelectual-acadêmica se tornam, na contemporaneidade, contextos nos quais as pautas de reconhecimento, valorização e produção de narrativas identitárias afirmativas passam a ser negociadas a todo momento pelos sujeitos que não se enquadram no modelo hegemônico científico branco eurocentrado.

Assim, não seria impreciso considerarmos que os referidos movimentos de lutas e conquistas de consolidação de espaços de produção de intelectualidade acadêmica no Brasil contemporâneo podem ser pensados como desdobramentos de ideias e princípios defendidos, por exemplo, pelo sociólogo negro Eduardo de Oliveira, que já na década de 1970 defendia e alertava para a potência de espaços de produção científica pensados a partir das vivências negras:

Vivemos num mundo onde a cor, a etnicidade e a classe social são de primordial importância, sendo assim impossível ao cientista (e em particular ao cientista negro) manter uma neutralidade valorativa. [...] São estas considerações que nos levam a ideia de uma sociologia negra (ou uma historiografia, economia, antropologia negras etc...). Ela surge como reação e revolta contra o viés da "sociologia principal" burguesa-liberal; como um passo positivo para o estabelecimento de definições básicas, conceitos e construções que utilizam a experiência histórica dos afro-brasileiros (OLIVEIRA, 1977, p. 26). 
A concepção de "ciência para o negro" parte da proposição de ruptura epistemológica dentro do campo da Sociologia. Todavia, os estudos de Oliveira (1977) reverberaram e contribuíram de modo importante para a consolidação de espaços de intelectualidade negra em outras áreas, como é o caso da Filosofia, História, Antropologia, Economia e Educação.

Eduardo de Oliveira diferencia a produção científica que ele nomeia como "principal" (sobretudo no âmbito da Universidade de São Paulo, nas décadas de 1970 e 1980), que se ocupava da temática racial a partir do olhar produtor de uma ciência sobre o negro, da proposta de "ciência para o negro". Esta última se sustenta na ideia de que as produções sobre as relações raciais no Brasil deveriam ser elaboradas a partir de pontos de vista que considerem a singularidade do sujeito negro que constrói sua própria história. Essa compreensão se opõe aos estudos que partem dos pressupostos do fazer científico, designado por ele de "burguês-liberal" e majoritariamente branco.

Ao longo das décadas e do desenvolvimento dos estudos no campo das Relações Étnico-Raciais, a noção de "ciência para o negro" se desdobra e se articula com outras perspectivas teórico-metodológicas, fazendo emergir possibilidades de análise sobre as ERER que propõem rupturas com as matrizes epistemológicas colonialistas, entre as quais, salientamos aqui, se enquadra a intelectual e pensadora negra Conceição Evaristo.

Histórias, vivências ou, conforme apresenta Conceição Evaristo (2017a; 2017b), "Escrevivências", não podem ser lidas como fábulas pela "casa-grande", mas como instrumentos que servem para incomodar os "seus sonos injustos". Também é preciso trazer maior visibilidade ao legado social, as identidades e textualidades afro-brasileiras que têm sido repassadas aos seus descendentes e que não são levadas em consideração pelos saberes ocidentais.

Logo, esforços têm sido feitos no intento de valorizar essas narrativas negrobrasileiras ou partes do que remanesce delas, mesmo após todas as rupturas socioculturais que incidiram negativamente nas suas dinâmicas de vida, por pesquisadoras e pesquisadores através de seus estudos, especialmente, por aqueles que se autodeclaram descendentes das etnias africanas presentes no Brasil.

As escreveduras transmitidas pela tradição oral, pelas linguagens artísticas e pela corporeidade negra, que Leda Maria Matins (1997) denomina de "Oralituras", são o que Antônio Risério (1993, p. 70), ao lembrar Roger Bastides, considera como inscrições corpóreas e "palavras negras que passam por nuvens brancas".

O protagonismo das populações negras brasileiras, sobretudo nos campos da ciência, cultura, arte e literatura, tem sofrido, ao longo do tempo, sufocamentos pelos mesmos que, no passado, promoveram políticas escravocratas e genocidas. Na Contemporaneidade, as tentativas de sufocamento dos saberes afro-brasileiros são provenientes de narrativas hegemônicas que concebem como centro da intelectualidade humana apenas saberes ocidentais de base eurocêntrica, deixando de fora outras epistemologias e, em última instância, contribuindo de forma deliberada na promoção do epistemicídio ${ }^{3}$ (SANTOS, 1999).

Nesse sentido, as ciências, saberes e identidades afro-brasileiras que são constituídas a partir das lutas sociais, como bem nos ensina Nilma Lino Gomes (2017), pelo senso de coletividade e da ancestralidade, dentre outros atravessamentos, têm 
sofrido reducionismos quando são interpretadas erroneamente por conceitos e narrativas coloniais, como se tais experiências coletivas, bem como os demais aspectos e particularidades desses sujeitos, formassem um conglomerado fixo e homogêneo. Esses fundamentos incongruentes visam estabelecer padrões que não se acomodam, nem mesmo se assemelham às concepções plurais das identidades e ciências produzidas pelos povos negros no Brasil.

São recorrentes os desafios encontrados por pesquisadoras/es para produzirem histórias que priorizem os saberes desvalorizados pelo epistemicídio, pelo racismo e por diferentes formas de discriminações. As narrativas identitárias negras são conduzidas ao esquecimento, por meio da invisibilização das comunidades negras brasileiras. Esse esquecimento no âmbito da produção acadêmica é promovido, não raras vezes, por pesquisas que abordam o tema das Relações Étnico-Raciais, todavia, recorrem a aportes teóricos e metodológicos que não dão conta de responder às variantes de diversidade e complexidade das populações negras brasileiras.

Nesse sentido, para alcançar o entendimento das produções dos conhecimentos e saberes dos povos negros no Brasil de forma mais aprofundada, bem como traduzi-los e evidenciá-los como fontes potentes e autorais do campo científico, pesquisadores e pesquisadoras voltam os seus olhares para as filosofias e metodologias desenvolvidas por esses sujeitos. Um exemplo pode ser encontrado no conceito de "Pretagogias", elaborado por Geranilde Costa e Silva (2013), e que tem como base conceitual valores oriundos das sociedades africanas relativos às premissas de coletividade, religiosidade como partes indissociáveis dos seres humanos, a tradição oral, entre outros princípios.

Assim como as "Pretagogias", muitos outros referenciais teórico-metodológicos, elaborados a partir das perspectivas e saberes africanos e afro-brasileiros, contribuem para a tradução e a sistematização dos saberes e produções científicas, a exemplo da metodologia de "catar folhas", elaborada por Marcio Goldman (2005), que, segundo os estudos de Beatriz Martins Moura (2019, p. 6), "é uma expressão usada pelas comunidades afro-religiosas para se referir, por exemplo, aos processos de aprendizado pelos quais uma pessoa passa, ao longo de toda a sua vida, em um terreiro".

A "Oralitura", termo cunhado por Leda Maria Martins (2003), opera como um eixo que valoriza a tradição oral africana/afro-brasileira como forma de trazer à tona suas experiências através dos seus corpos, numa escrita de si, bem como as "Afrografias" (MARTINS, 1997), que são as memórias e as experiências da negritude. Ainda nesse mesmo sentido, outro conceito que contribui no processo narrativo como uma potente ferramenta teórico-metodológica é o de "Escrevivência" de Conceição Evaristo (2017a; 2018b). A "Escrevivência" como referencial tem contribuído para que mulheres e homens negras/os, pesquisadoras e pesquisadores, bem como outros grupos sociais, que foram marginalizados no decorrer da história pela negação e opressão do Estado, possam enunciar suas perspectivas na sociedade, seus históricos de vida e suas participações como sujeitos protagonistas a partir de suas próprias lentes. 
EVANGELISTA, L. de O.; SIQUEIRA, C. de F. C.; ROCHA, C. M. F.

\section{NARRATIVAS AUTOBIOGRÁFICAS E PRODUÇÃO CIENTÍFICA DE PESQUISADORES/AS NEGROS/AS}

A heterogeneidade e a multiplicidade negra reúnem inúmeros repertórios de experiências sociais e saberes que não se resumem a uma identidade essencial a partir das perspectivas e lentes eurocêntricas. O "conjunto de experiências negras", as quais se refere Stuart Hall (2003, p. 346), operam como um potente propulsor que auxilia essa diversidade, sobretudo no que se refere ao campo da produção intelectual acadêmica:

Nasci numa madrugada de segunda-feira, em Recife-PE. Olorúm, incumbiu ao orixá Odé, o deus caçador e da caça do panteão iorubano, senhor da floresta e de todos os seres que nela habitam, ser o dono do meu Ori (cabeça), mas também me deu uma lá para tomar conta do meu coração: lemanjá, a rainha das águas salgadas [...] Meu caminho já começava a ficar marcado com ancestralidades afro-brasileiras (FILIZOLA, 2019, p. 14).

[...] Hoje, estar pesquisando sobre a temática do racismo religioso, que é fruto de um racismo estruturante das relações sociais, é voltar ao presente um passado não muito distante (FILIZOLA, 2019, p. 19).

Também chamadas de autoetnografias, as narrativas autobiográficas são entendidas aqui como narrativas de vivências utilizadas como procedimentos metodológicos. Elas podem operar tanto como processos investigativos quanto como resultados das produções realizadas pelas/os pesquisadoras/es negras/os, na perspectiva que visa responder, assertivamente, a questões sociais das pesquisas, uma vez que "somos sempre diferentes e estamos sempre negociando diferentes tipos de diferenças" (HALL, 2003, p. 346). Esse entendimento pode ser observado, por exemplo, a partir da recorrência de relatos que lançam mão da autodeclaração étnico-racial como ponto de partida da escrita acadêmica:

É com grande alegria e luta que uma mulher negra, filha de septuagenários de cidade simples da região metropolitana de Porto Alegre/RS, conseguiu chegar até aqui, no Programa de PósGraduação em Educação, na Universidade Federal do Rio Grande do Sul, para apresentar-lhes neste momento, a tese doutoral, que recebe o título de Saberes das Mulheres Veteranas na Economia Solidária: Sororidade a Outra Educação! (ALVES, 2014, p. 15).

[...] de forma breve, esses são alguns dos lugares dos quais falo como mulher afro-brasileira, como pesquisadora. Esses espaços me ajudam a refletir [...] a respeito da relação da educação com a identidade afro-brasileira e o papel que temos de construir uma pedagogia da diversidade, que visibilize a real participação do/a afro-brasileiro/a na história, economia e cultura do Brasil, problematizando com isso os processos históricos de invisibilização que nos afetam (CORREIA, 2018, p. 38). 
A partir da investigação sobre as assimetrias raciais, sociais e de gênero que silenciam e interditam a inserção das populações negras nos espaços de conhecimento, Sueli Carneiro (2005) propõe a constituição de novas bases epistemológicas, que tomam as experiências de si como elementos basilares da produção de conhecimento descentralizado, em oposição à lógica universal. Essa conduta identitária afirmativa pode ser percebida na Dissertação de Mestrado da pesquisadora Elisabeth Santos Natel:

\begin{abstract}
Hoje, eu me identifico como mulher afrodescendente. Antes, não me reconhecia como mulher negra e agora pretendo conhecer as narrativas das mulheres negras profissionais, no meio acadêmico, universitárias. O identificar-me como ser afrodescendente, o ser afrodescendente que sou hoje, é o resultado da minha saga identitária. Tem significado imensurável para mim, pois são as histórias de vida que dimensionam a autoestima, que movem e impulsionam as ações de um sujeito (NATEL, 2014, p. 16).
\end{abstract}

Nessa direção, entendemos que a ideia de "escrevivência" se vincula a esse modo de elaboração de novas epistemologias que partem do ponto de vista autoral e protagonista, como é o caso do relato feito pelo pesquisador Raphael Rodrigues Vieira Filho (2018) a respeito de um encontro acadêmico na Associação Nacional de História:

\begin{abstract}
Lembro-me de uma Mesa na ANPUH em que todos éramos negros discutindo história de populações negras e com uma sala lotada de outros jovens pesquisadores interessados no assunto, isso em meados da década de 1990. Todos nós levamos ou adaptamos nossas pesquisas para nossas instituições tendo como compromisso a orientação e formação de novos pesquisadores negros. Isso possibilitou o fortalecimento do campo e visão de pesquisa em que atuávamos. Mais tarde quase todos assumiram compromisso com a fundação ou fortalecimento de núcleos de estudos nas instituições de atuação e os contatos anteriores facilitaram a organização de redes colaborativas (VIEIRA FILHO, 2018, p. 364).
\end{abstract}

As populações negras brasileiras estiveram no cerne de múltiplas narrativas, produzidas não em linha histórica única, mas por meio de uma rede complexa de discursividades produtoras de modos de ser negro/a no Brasil. As narrativas identitárias afirmativas da negritude elaboram um terreno fecundo para importantes redimensionamentos identitários e históricos que reivindicam a legitimidade de os sujeitos negros se constituírem enquanto sujeitos de conhecimento e colocam em questionamento uma série de ditames a respeito das dinâmicas sociais hegemônicas, conforme destaca a pesquisadora Lucilene Reginaldo a respeito dos debates em torno da criação de espaços de produção intelectual acadêmica de pesquisadoras/es negras/os: 
EVANGELISTA, L. de O.; SIQUEIRA, C. de F. C.; ROCHA, C. M. F.

[...] não tenho dúvidas de que toda a discussão era regada pelo interesse no protagonismo dos negros. Protagonismo em dois sentidos: atentar para temas e problemas que apresentavam os sujeitos, as escolhas e práticas dos grupos negros e, ao mesmo tempo, ressaltar a contribuição das análises dos pesquisadores negros (REGINALDO, 2018, p. 349).

No decorrer dessa e de outras escritas semelhantes, podem ser observados diferentes elementos por meio dos quais as/os pesquisadoras/es negras/os se posicionam e se colocam no texto enquanto sujeitos políticos implicados no texto, mostrando que os fatores de autodeclaração, afirmação identitária e postura pesquisadora constituem uma relação indissolúvel. Ou seja, ser pesquisadora(o), nesse caso, está diretamente relacionado com a pertença étnico-racial:

Esta dissertação reúne parte das minhas inquietações como pesquisadora da área de Serviço Social e integrante do movimento negro. As problematizações e reflexões na minha trajetória acadêmica sempre estiveram direcionadas a contribuir, do ponto de vista profissional, com a "escola" que me formou como mulher negra: A educação comunitária. [...] Afirmar-me afro-brasileira é algo que desvela um processo de tornar-me mulher afro-brasileira. Lembro-me quando as questões feministas e de gênero me instigavam na adolescência e juventude, como gostava de ler os livros que faziam reflexões críticas sobre a sociedade, os quais estavam na biblioteca de minha mãe, que é professora universitária. [...] Em minha trajetória vou percebendo que inúmeras coisas influenciam minha identidade, o papel social que ocupo, sendo que a sociedade constantemente me mostrava/mostra "o não-lugar social" da mulher afro-brasileira. Porém, até parte da minha trajetória a percepção da questão racial não estava tão evidenciada em meus escritos. Por isso, como afirma Lélia Gonzalez (1988, p. 2) ao refletir sobre a célebre frase de Simone de Beauvoir, "[...] tornarse negra é uma conquista". Meu processo de empoderamento se intensificou a partir da militância no feminismo negro, no movimento de mulheres negras (CORREIA, 2018, p. 33).

A partir do que defende Sueli Carneiro (2005), consideramos que esse modo de se colocar no texto possibilita um determinado modo de transformação da existência enquanto pesquisador/a negro/a que passa pela autoria do conhecimento e, ao mesmo tempo, toma a experiência como propulsora do fazer científico. Compreendemos, portanto, que a proposta do fazer científico a partir da experiência de si, da singularidade do ser e da negativa aos sistemas explicativos universais, conforme discorre a filósofa Sueli Carneiro, em consonância com o conceito de "Escrevivências" da escritora Conceição Evaristo, aponta para uma importante prática de resistência por meio da qual são colocadas em funcionamento técnicas produtoras de novas subjetividades negras pesquisadoras emergentes. 


\section{CONSIDERAÇÕES FINAIS}

Para a realização deste estudo, escrito a seis mãos, partimos das reflexões e vivências de pesquisa do autor e das autoras, em particular do pesquisador negro, com relação aos processos de construção identitária acadêmica negra. Em parceria com duas colegas brancas, foram empreendidos esforços acadêmicos no intuito de realizar reflexões a respeito dos percursos intelectuais constituídos a partir das Relações ÉtnicoRaciais nos contextos de produção acadêmico-científica.

Apresentamos este artigo como uma ampliação interpretativa de referências e conceitos importantes para os estudos voltados ao campo da Educação das Relações Étnico-Raciais (ERER), bem como aos movimentos sociais antirracismo contemporâneos. Desse modo, traçamos como objetivo deste estudo analisar de que modo o conceito de "Escrevivências", cunhado pela pensadora e escritora negra Conceição Evaristo (2017a; 2017b), bem como os desdobramentos acadêmicos que lançam mão das narrativas autobiográficas e experiências de si como instrumentos de escrita acadêmica, têm sido operados como recursos teóricos e metodológicos estratégicos importantes para a produção científica de pesquisadoras/es negras/os.

Como escolha metodológica, optamos por analisar trabalhos acadêmicos de pesquisadoras/es autodeclaradas/os negras/os, selecionados no ambiente virtual da Associação Brasileira de Pesquisadores/as Negros/as, no espaço dedicado a divulgar as produções científicas de pesquisadores associados à entidade.

No desenvolvimento deste estudo, analisamos a construção de narrativas autobiográficas dentro das produções acadêmico-científicas como elemento de afirmação autoral, política e identitária de uma escrita que parte da existência negra como ponto propulsor do fazer científico. Analisamos que estabelecer uma demarcação identitária, política e autodeclarada negra na composição da escrita acadêmica significa colocar em funcionamento uma conduta específica no âmbito da pesquisa, ou seja, um modo de ser e de fazer pesquisa que passa, necessariamente, pela afirmação da própria negritude. Desse modo, entendemos que a ideia de "Escrevivências" funciona como um forte componente da constituição de novas bases epistemológicas que buscam romper com padrões.

Entendemos, portanto, que a forma de se posicionar no texto como sujeito autor-negro permite uma maneira específica de transformar a si mesmo, ou seja, permite a constituição de uma existência negra como pesquisador/a negro/a que é atravessada, necessariamente, pela autoria autodeclarada na pesquisa. Ao mesmo tempo, parte da experiência de si como elemento de eclosão do fazer científico. Consideramos, nesse sentido, que a ideia de uma produção de conhecimento que parte das experiências de si, das singularidades, da afirmação identitária e do afastamento dos referenciais teóricos hegemônicos e eurocentrados indicam modos de resistência importantes e produtivos no âmbito acadêmico-intelectual. Esses modos de resistência colocam em operação técnicas constituintes de novas subjetividades negras pesquisadoras que delineiam outras bases epistemológicas para o contexto da pesquisa brasileira contemporânea. 
EVANGELISTA, L. de O.; SIQUEIRA, C. de F. C.; ROCHA, C. M. F.

Artigo recebido em: 28/02/2021

Aprovado para publicação em: 14/10/2021

\section{"ESCREVIVÊNCIAS", AUTOBIOGRAPHIC NARRATIVES AND BLACK INTELLECTUALITY: ACADEMIC WRITING AS RESISTANCE}

ABSTRACT: Based on concepts and references from studies focused on the Education of EthnicRacial Relations, this text aims to carry out an analysis of how the concept of "Escrevivências", elaborated by the black writer and thinker Conceição Evaristo, has worked as a theoretical and methodological framework for the production and writing of academic productions by black researchers. Therefore, we look at a set of academic works published in the virtual environment of the Brazilian Association of Black Researchers (ABPN) and, from the selected materials, we analyze that the construction of black autobiographical narratives, within the academic-scientific scope, operate as an important theoretical and methodological resource regarding the making and writing of science in a protagonist, authorial, political and avowedly affirmative manner by black researchers in contemporary Brazil.

KEYWORDS: Education of Ethnic-Racial Relations. Self-narratives. Cultural Studies.

\section{"ESCREVIVÊNCIAS", NARRATIVAS AUTOBIOGRÁFICAS E INTELECTUALIDAD NEGRA: LA ESCRITURA ACADÉMICA COMO RESISTENCIA}

RESUMEN: A partir de conceptos y referencias de estudios centrados en la Educación de las Relaciones Étnico-Raciales, este texto tiene como objetivo realizar un análisis sobre el modo como el concepto de "Escrevivências", elaborado por la escritora y pensadora negra Conceição Evaristo, ha funcionado como un recurso teórico y metodológico para la producción y redacción de producciones académicas de investigadores/as negros/as. Por lo tanto, analizamos un conjunto de trabajos académicos publicados en el sitio virtual de la Asociación Brasileña de Investigadores/as Negros/as y, a partir de los materiales seleccionados, analizamos que la construcción de narrativas autobiográficas negras, en el ámbito académico-científico, ha operado como un importante recurso teórico y metodológico sobre la producción y escrita de la ciencia de manera protagonista, autoral, política y claramente afirmativa por parte de investigadores/as negros/as en el Brasil contemporáneo.

PALABRAS CLAVE: Educación en Relaciones Étnico-Raciales. Auto-narrativas. Estudios Culturales.

\section{NOTAS}

1 - A Constituição Federal de 1988 (BRASIL, 1988) assume o termo "diversidade" para se referir à multiplicidade étnico-racial, cultural e social existente no Brasil como uma potente característica identitária da nação. Desse modo, visa garantir aos diferentes grupos sociais que compõem a 
população do país o direito à cultura própria. No que tange o tema das garantias aos diferentes grupos populacionais, a Constituição vigente também torna o racismo um crime imprescritível e inafiançável. No âmbito escolar, a temática da diversidade compõe os Parâmetros Curriculares Nacionais (PCN's) como um tema transversal a ser trabalhado em consonância ao currículo escolar regular (BRASIL, 1997).

2 - Azânia Nogueira, Joana Célia dos Passos e Tânia Mara Cruz (2013, p. 293) afirmam que a criação da ABPN "se dá a partir do I Encontro de Docentes e Pesquisadores e Pós Graduandos Negros das Universidades Paulistas: A produção do saber e suas especificidades, realizado de 21 a 23 de setembro de 1989, na Universidade Estadual de São Paulo (UNESP), Campus de Marília. A principal preocupação do Encontro foi proporcionar um momento de contato e trocas entre os docentes, pesquisadores e pós-graduandos negros das diversas instituições paulistas; garantir a inserção da questão racial na democratização do espaço universitário e possibilitar o intercâmbio e a inclusão de temas que resgatassem as origens africanas como a atuação de pesquisadores negros enquanto agentes sociais".

3 - O conceito de "epistemicídio" foi idealizado por Boaventura de Souza Santos. Este termo designa "uma dominação epistemológica, uma relação extremamente desigual de saber-poder que conduziu à supressão de muitas formas de saber próprias dos povos e nações colonizados, relegando muitos outros saberes para um espaço de subalternidade" (SANTOS; MENESES, 2010, p. 7).

\section{REFERÊNCIAS}

ABPN. ASSOCIAÇÃO BRASILEIRA DE PESQUISADORES/AS NEGROS/AS. Estatuto da Associação Brasileira de Pesquisadores/As Negros/As.: ABPN, 2002. Brasília.

ALVES, Simone Silva. Saberes das Mulheres Veteranas na Economia Solidária: Sororidade A Outra Educação. 2014. Tese (Doutorado em Educação) - Faculdade de Educação, Universidade Federal do Rio Grande do Sul, Porto Alegre, 2014.

BRASIL. Constituição da República Federativa do Brasil. Brasília: Senado Federal, 1988.

BRASIL. Lei 10.639. Institui a obrigatoriedade do Ensino de História e Cultura Afrobrasileira e Africana na Educação Básica. Presidência da República Federativa do Brasil. Brasília, 2003.

BRASIL. Lei 12.288. Estatuto da Igualdade Racial. Presidência da República Federativa do Brasil. Brasília, 2010.

BRASIL. Lei 12.711. Lei de cotas para o Ensino Superior. Presidência da República Federativa do Brasil. Brasília, 2012.

BRASIL. Ministério da Educação. Parâmetros Curriculares Nacionais para o Ensino Fundamental. Brasília: MEC, 1997. 
EVANGELISTA, L. de O.; SIQUEIRA, C. de F. C.; ROCHA, C. M. F.

CARNEIRO, Aparecida Sueli. A construção do outro como não-ser como fundamento do ser. 339f. Tese (Doutorado em Educação) - Faculdade de Educação, Universidade de São Paulo, São Paulo, 2005.

CORREIA, Aline Nascimento Santos. Determinantes do Silenciamento da Questão Étnico-Racial no Serviço Social Brasileiro. Dissertação de Mestrado (Mestrado em Serviço Social) - Pró-Reitoria de Pós-Graduação e Pesquisa, Universidade Federal de Sergipe, Sergipe, 2018.

DOMINGUES, Petrônio. Espaço Aberto Ações afirmativas para negros no Brasil: o início de uma reparação histórica. Revista Brasileira de Educação, Rio de Janeiro, n. 29, p. 164-176, 2005.

EVARISTO, Conceição. Becos da memória. Rio de Janeiro: Pallas, 2017 a.

EVARISTO, Conceição. Poemas da recordação e outros movimentos. Rio de Janeiro: Malê, 2017b.

FILIZOLA, Gustavo Jaime. As Crianças de Candomblé e a Escola: Pensando sobre o racismo religioso. 213f. Dissertação (Mestrado em Educação, Culturas e Identidades) Departamento de Educação, Universidade Federal Rural de Pernambuco, Recife, 2019.

GOLDMAN, Márcio. Formas do Saber e Modos do Ser: Observações Sobre Multiplicidade e Ontologia no Candomblé. Religião \& Sociedade. Rio de Janeiro, v. 25, n. 2, p. 102-120, 2005.

GOMES, Nilma Lino. O Movimento Negro educador: saberes construídos nas lutas por emancipação. Petrópolis: RJ, Vozes, 2017.

GONÇALVES, Luiz Alberto Oliveira; SILVA, Petronilha Beatriz Gonçalves. Movimento Negro e Educação. Revista Brasileira de Educação, Rio de Janeiro, s. v., n. 15, p. 134-158, 2000.

GONZALES, Zuleika Kohle. Formas da igualdade nas ações afirmativas: enfrentamentos à formalização e ao exclusivismo no acesso ao ensino superior. 2015. 119f. Tese. (Doutorado em Psicologia Social e Institucional) - Instituto de Psicologia, UFRGS, Porto Alegre, 2015.

HALL, Stuart. Que "negro" é esse na cultura negra?. In:SOVIK; Liv (org.). Da diáspora: Identidades e mediações culturais. Trad. Adelaine LaGuardia Resende. Belo Horizonte: Editora UFMG; Brasília: Representação da UNESCO no Brasil, 2003. p. 335-349.

MARTINS, Leda. Afrografias da Memória. São Paulo: Perspectiva, 1997. 
"Escrevivências", narrativas autobiográficas e intelectualidade negra:...

Dossiê 1343

MARTINS, Leda. Performances da oralitura: corpo, lugar da memória. Letras (Santa

Maria), Santa Maria, v. 25, n. 26, p. 55-71, 2003.

MOURA, Beatriz Martins. Catar Folhas: Articulação de Conhecimentos no Chão dos Terreiros de Candomblé. Revista Opara - Ciências Contemporâneas Aplicadas, ISSN 2237-9991, FACAPE, Petrolina, v. 9, n. 2, p. 2-18, maio/ago, 2019.

NATEL, Elisabeth dos Santos. Educação das Relações Étnico-Raciais: As Sagas e Resiliências das Mulheres Negras Profissionais: em Três Ambientes Universitários. Dissertação (Mestrado em Educação) - Unidade Acadêmica de Pesquisa e PósGraduação, Unisinos, São Leopoldo, 2014.

NOGUEIRA, Azânia Mahin Romão; DOS PASSOS, Joana Célia; CRUZ, Tânia Mara. A participação das pesquisadoras negras na produção do conhecimento científico. Identidade! São Leopoldo, v. 18, n. 3, p. 291-302, 2013

OLIVEIRA, Eduardo de. Etnia e Compromisso Intelectual. In: GRUPO DE TRABALHO ANDRÉ REBOUÇAS (org.). Semana de Estudos Sobre o Negro na Formação Social Brasileira, 2., 1977, Niterói. Caderno de Estudos. Niterói: Universidade Federal Fluminense, 1977. p. 22- 28.

OLIVEN, ARABELA CAMPOS; BELLO, L. Negros e indígenas ocupam o templo branco. Horizontes Antropológicos, Porto Alegre, ano 23, n. 49, p. 339-374, set./dez. 2017. http://dx.doi.org/10.1590/S0104-71832017000300013

RISÉRIO, Antônio. Textos e tribos - poéticas extraocidentais nos trópicos brasileiros. Rio de Janeiro: Imago, 1993.

REGINALDO, Luciane. REVISTA DA ABPN. GOMES, Flávio; DOMINGUES, Petrônio. [Entrevistas] Intelectuais Negras/Negros: Gerações, Legados e Protagonismos - A Geração PUC-SP. Revista da Associação Brasileira de Pesquisadores/as Negros/as (ABPN), Brasília, v. 10, n. 25, p. 346-372, 2018.

SANTOS, Boaventura de Sousa. Pela Mão de Alice. O Social e o Político na PósModernidade. 7०. ed. Porto: Edições Afrontamento, 1999.

SANTOS, Boaventura de Sousa; MENESES, Maria Paula. (org.). Epistemologias do Sul. São Paulo: Cortez, 2010.

SILVA, Genilde Costa e. Pretagogia: construindo um referencial teórico-metodológico de matriz africana para a formação de professores/as. 2013. 243f. - Tese (Doutorado em Educação) - Faculdade de Educação, Universidade Federal do Ceará, Fortaleza - CE, 2013. 
EVANGELISTA, L. de O.; SIQUEIRA, C. de F. C.; ROCHA, C. M. F.

SISS, Ahyas; OLIVEIRA, lolanda de. Trinta anos de ANPED, as pesquisas sobre a educação dos afro-brasileiros e o GT-21: marcas de uma trajetória. In: Reunião anual da Anped, 30., 2007, Caxambu. Anais [...]. Caxambu: ANPED, 2007. Disponível em: https://anped.org.br/sites/default/files/trabalho_encomendado_gt21-_ahyas__int_.pdf. Acesso em: 27 out. 2021.

SODRÉ, Muniz. Claros e escuros: identidade, povo e mídia no Brasil. 3. ed. Petrópolis: Vozes, 2015.

VIEIRA FILHO, Raphael Rodrigues. Entrevista. Revista da ABPN, s. I., v. 10, n. 25, mar.-jun. 2018, p. 346-372.

LÁZARo de Olivelra Evangelista: Doutorando e Mestre em Educação pela Universidade Federal do Rio Grande do Sul (UFRGS. Pós-graduado no curso de Especialização em Metodologia do Ensino da Língua Inglesa pela Faculdade de Tecnologia e Ciência da Bahia, (FTC) - Salvador - BA. Pedagoso graduado pelo Centro Universitário Internacional (UNINTER). Graduado em Gestão de Negócios em Turismo pela Faculdade de Turismo da Bahia / Faculdades Integradas Olga Mettig, (FACTUR / FAMETTIG) - Salvador - BA e Graduado no curso de Licenciatura em Letras / Língua Inglesa e Respectivas Literaturas pela (PUCRS) - Porto Alegre - RS.

Orcid: https://orcid.ors/0000-0003-0131-571X

E-mail: lazarusevangelista@gmail.com

Carolina de Freitas Corrêa Siqueira: Doutoranda em Educação pelo Programa de Pósgraduação em Educação da Universidade Federal do Rio Grande do Sul (PPGEduUFRGS). Mestra em Educação pelo Programa de Pós-graduação em Educação da Universidade de Santa Cruz do Sul (PPGEdu - UNISC) Licenciada em História pela Universidade de Santa Cruz do Sul. Bolsista do Programa de Excelência Acadêmica (PROEX-CAPES).

Orcid: https://orcid. org/0000-0002-2680-6083

E-mail: carolinatcsiqueira@smail.com

Cristianne Maria Famer Rocha: Doutora e Mestre em Educação pela Universidade Federal do Rio Grande do Sul (PPGEDU/UFRGS). Professora Associada II da Escola de Enfermagem da Universidade Federal do Rio Grande do Sul (UFRGS). Atua junto ao Curso de Bacharelado em Saúde Coletiva. Professora Permanente do Programa de PósGraduação em Enfermagem (PPGENF/UFRGS) e do Programa de Pós-Graduação em Educação (PPGEDU/UFRGS).

Orcid: https://orcid. org/0000-0003-3281-2911

E-mail: rcristianne@gmail.com

Este periódico utiliza a licença Creative Commons Attribution 3.0, para periódicos de acesso aberto (Open Archives Initiative - OAI). 